\title{
Determinação do ponto de carga zero da bauxita da região nordeste do Pará
}

\section{(Determination of the zero point of charge of the northeast of Pará bauxite)}

\author{
R. L. S. Pinto, K. C. S. Silva, D. N. P. Cardoso, E. N. Macêdo, A. M. P. F. Felipe \\ Laboratório de Reologia, Instituto de Tecnologia, Universidade Federal do Pará, \\ R. Augusto Corrêa 01, Belém, PA 66075-110 \\ rayssa.luana@hotmail.com,dilson_ufpa@yahoo.com.br,sarmentokelly@yahoo.com.br, \\ enegrao@ufpa.br,ampf@ufpa.br
}

\begin{abstract}
Resumo
No nordeste do Pará o transporte da polpa de bauxita é através de mineroduto, sendo a viscosidade um parâmetro de controle fundamental para o bombeamento do minério. Este estudo ilustra a influência do pH na reologia da polpa por meio da determinação do ponto de carga zero (pHpcz) da bauxita. Foram efetuadas análise granulométrica, microscopia eletrônica de varredura, ensaios potenciométricos testando o cloreto de amônia como eletrólito indiferente e ensaios reológicos em diferentes valores de $\mathrm{pH}$. Os resultados revelaram que o cloreto de amônia pode ser utilizado como eletrólito indiferente para esse tipo de análise e que ocorre a redução da viscosidade em valores de $\mathrm{pH}$ distantes do ponto de carga zero.
\end{abstract}

Palavras-chave: polpa de bauxita, reologia, ponto de carga zero, viscosidade.

Abstract

In the northeast of Pará, Brazil, the transport of bauxite pulp is through pipeline, being the viscosity a parameter which can interfere in the pumping. This study illustrates the influence of pH on pulp rheology through of determination of the zero point of charge. Were done particle size analysis, SEM, EDS, potentiometric tests testing ammonia chloride as indifferent electrolyte and rheological tests at different $\mathrm{pH}$ values. The results revealed that ammonia chloride can be used as indifferent electrolyte and showed a decrease in viscosity when there is far of the zero point of charge.

Keywords: bauxite pulp, rheology, zero point of charge, viscosity.

\section{INTRODUÇÃO}

O Brasil é o terceiro maior produtor de bauxita. O estado do Pará é responsável por $75 \%$ da exploração desse minério no país [1]. A polpa de bauxita da região de Paragominas, PA, está sendo transportada por mineroduto e a viscosidade desse produto é um parâmetro muito importante no transporte uma vez que, numa eventual parada do processo ocorre à sedimentação das partículas, formando massas compactadas do minério, que dificultam o bombeamento. $\mathrm{O}$ pH da polpa é um parâmetro que deverá ser monitorado, pois influencia na viscosidade da polpa de bauxita, pois interfere no equilíbrio de cargas. O fluxo de partículas em suspensão é expressivamente afetado por suas cargas elétricas superficiais e pelo controle do $\mathrm{pH}$ pode-se preliminarmente controlar as cargas superficiais da suspensão [2]. Cada partícula terá inicialmente uma carga superficial que é positiva, negativa ou neutra, já que a suspensão tem um valor de $\mathrm{pH}$ que está abaixo, acima ou é o pH que corresponde ao ponto de carga zero da partícula. A determinação do ponto de carga zero, ou seja, do $\mathrm{pH}$ em que as cargas dos sítios positivos e negativos se igualam torna-se fundamental, para que se possa avaliar o pH ótimo em que a polpa deve ser transportada, levando em consideração que afastando-se do $\mathrm{pH}$ em que ocorre o ponto de carga zero, a viscosidade tende a ser menor.

O objetivo do trabalho é determinar o ponto de carga zero, pelo procedimento de Van Raij and Peech, ou seja, o $\mathrm{pH}$ (pHpcz) em que as cargas dos sítios positivos e negativos se igualam [2], através dos dados de titulação potenciométrica, que determina de acordo com a variação do $\mathrm{pH}$ do meio as concentrações dos grupamentos positivos, negativos e neutros. Além de avaliar se o cloreto de amônia é um eletrólito indiferente a superfície da bauxita e verificar a influência do $\mathrm{pH}$ na viscosidade da polpa através do ponto de carga zero.

\section{EXPERIMENTAL}

A matéria-prima utilizada foi bauxita da região 


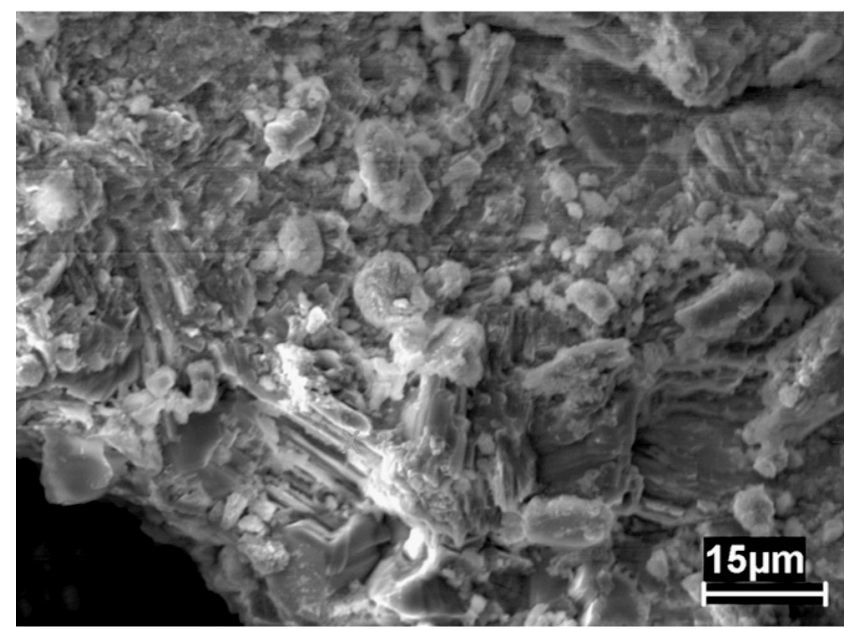

Figura 1: Fotomicrografia MEV da bauxita .

[Figure 1: SEM photomicrograph of bauxite.]

Tabela I - Concentração dos elementos químicos na amostra de bauxita.

[Table I - Chemical elements concentration in bauxite sample.]

\begin{tabular}{cccccc}
\hline Elemento & $\mathrm{O}$ & $\mathrm{Na}$ & $\mathrm{Al}$ & $\mathrm{Si}$ & $\mathrm{Fe}$ \\
\hline Conc. (\%) & 68,58 & 0,41 & 26,24 & 1,87 & 2,42 \\
\hline
\end{tabular}

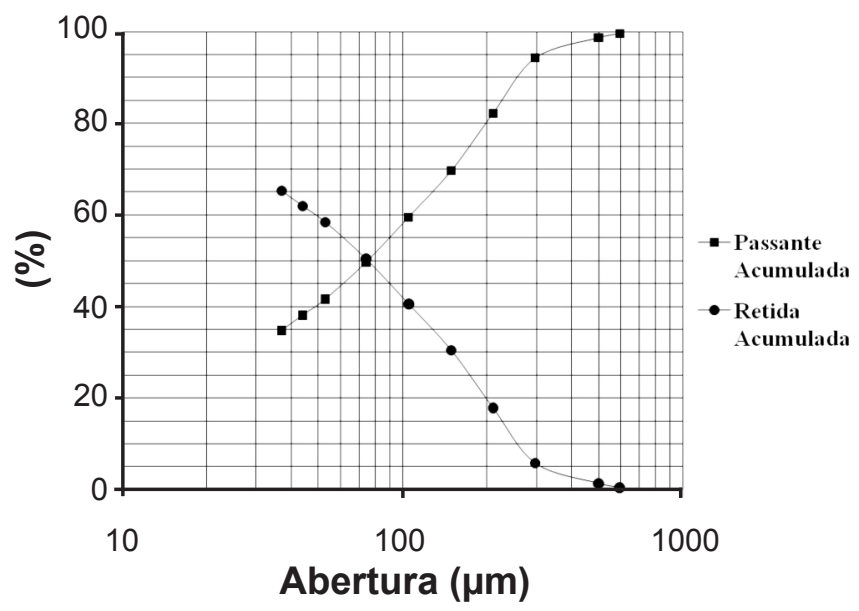

Figura 2: Distribuição granulométrica em porcentagem retida acumulada e passante acumulada.

[Figure 2: Particle size distribution in accumulated retained percentage and accumulated passing.]

nordeste do estado do Pará. Soluções de cloreto de amônia $1 \mathrm{~N}, 0,1 \mathrm{~N}, 0,01 \mathrm{~N}$ e $0,001 \mathrm{~N}$ foram usadas na preparação das suspensões de bauxita, que tiveram $\mathrm{pH}$ ajustado com ácido clorídrico $0,1 \mathrm{~N}$ e posteriormente, foram tituladas com hidróxido de sódio $0,1 \mathrm{~N}$. Foi feita a caracterização morfológica da polpa de bauxita: composição, ponto de carga zero e viscosidade. A morfologia das partículas de bauxita foi obtida por microscopia eletrônica de varredura (MEV) em equipamento Leo 1450VP, acoplado a um sistema de obtenção e identificação de padrões de difração

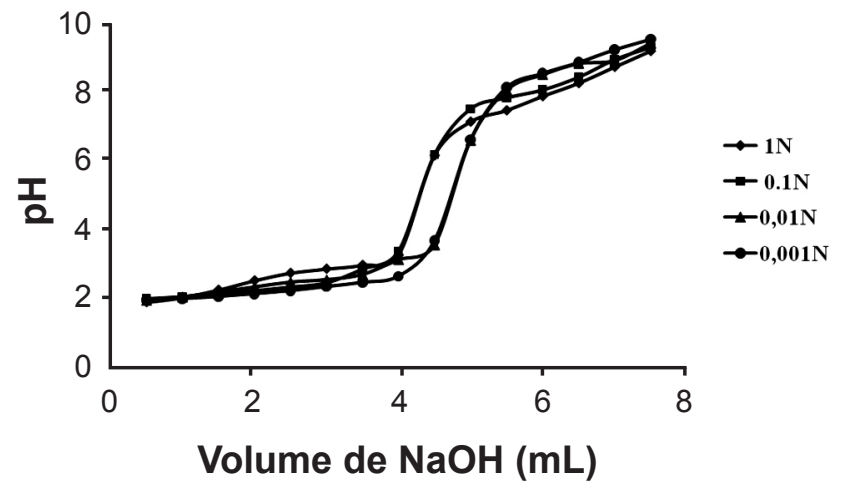

Figura 3: Determinação do ponto de carga zero da amostra de bauxita.

[Figure 3: Determination of the zero point of charge of the bauxite sample.]

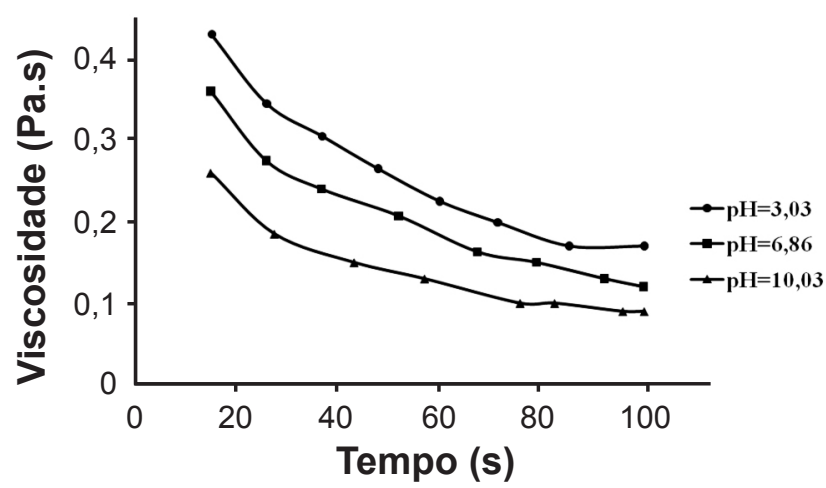

Figura 4: Viscosidade da polpa de bauxita com $50 \%$ em peso de sólidos em função do tempo, parametrizado no $\mathrm{pH}$ e em taxa de cisalhamento constante de $100 \mathrm{~s}^{-1}$

[Figure 4: Bauxite pulp viscosity with $50 \mathrm{wt} \%$ solids as a function of time, parametrized in $\mathrm{pH}$ and constant shear rate of $\left.100 \mathrm{~s}^{-1}.\right]$

de elétrons retroespalhados, que forneceu, por meio da espectroscopia de raios $\mathrm{X}$ dispersivos em energia (EDS), a composição das amostras.

Oponto de carga zero foi determinado por meio de titulação potenciométrica, em pHmetro de bancada digital Hanna HI 9321. A viscosidade foi analisada em um viscosímetro Haake VT 550 com sensor tipo cilindros coaxiais $\mathrm{SV}_{1}$ fixando taxa de cisalhamento de $100 \mathrm{~s}^{-1}$ a $28{ }^{\circ} \mathrm{C}$ durante $100 \mathrm{~s}$.

\section{RESULTADOS E DISCUSSÃO}

A análise em amostra de bauxita com fração abaixo de $37 \mu \mathrm{m}$ com microscopia eletrônica de varredura mostrou os aspectos microestruturais, representados na Fig. 1.

As análises de EDS foram feitas com duas amostras em triplicata. A média dos resultados qualitativos e semiquantitativos dos elementos constituintes é mostrada na Tabela I.

A composição típica da bauxita direcionada para metalurgia é: $45-55 \% \quad \mathrm{Al}_{2} \mathrm{O}_{3} ; 0-15 \% \quad \mathrm{SiO}_{2}$ total; 5-30\% $\mathrm{Fe}_{2} \mathrm{O}_{3} ; 0-6 \% \mathrm{TiO}_{2}[1]$. Os resultados da pesquisa mostraram 
que o teor de $\mathrm{Al}_{2} \mathrm{O}_{3}$ corresponde a 49,6\%, encontrando-se dentro da faixa de valor comercial.

A distribuição granulométrica representada pela Fig. 2 mostrou que $34,7 \%$ das partículas de bauxita estão abaixo de $37 \mu \mathrm{m}, 32,6 \%$ estão entre 38 e $150 \mu \mathrm{m}$ e 29,9\% estão acima de $150 \mu \mathrm{m}$. Observou-se ainda que diâmetro médio das partículas é de $1,79 \mathrm{~mm}$.

O procedimento-padrão para a determinação de um eletrólito indiferente baseia-se na construção de curvas em diversas concentrações do eletrólito avaliado. Curvas com um mesmo ponto de mudança brusca no $\mathrm{pH}$ sugerem espécies iônicas indiferentes à superfície da partícula [3]. A Fig. 3 ilustra a variação do $\mathrm{pH}$ da polpa de bauxita em função do volume de titulante $\mathrm{NaOH} 0,1 \mathrm{~N}$ e da concentração de $\mathrm{NH}_{4} \mathrm{Cl}$. Verifica-se que as curvas sofrem inflexão aproximadamente no mesmo ponto de carga zero $(\mathrm{pH}=3,48)$, ou seja, as partículas são independentes da força iônica do cloreto de amônia na faixa de concentração utilizada [4].

Segundo a metodologia utilizada, o ponto de carga zero ocorre no valor em que o $\mathrm{pH}$ da suspensão de bauxita muda bruscamente, ou seja, em torno deste valor de $\mathrm{pH}$, a amostra alcança a neutralidade das suas cargas superficiais [2-5]. De acordo com a Fig. 3 esse valor de $\mathrm{pH}$ foi de 3,48.

A Fig. 4 confirma a influência do ponto de carga zero (pHpcz) na viscosidade da polpa de bauxita.

Em valores de $\mathrm{pH}$ próximos ao ponto de carga zero, a superfície da bauxita encontra-se neutra e disponível para a adsorção, já em valores de $\mathrm{pH}$ afastados dele, a superfície das partículas tende a estar carregada e a semelhança entre as cargas, poderá provocar a repulsão entre elas favorecendo o escoamento uma vez que, a viscosidade tenderá a reduzir.

\section{CONCLUSÕES}

Por meio de titulação potenciométrica confirmou-se que o $\mathrm{NH}_{4}$ Clé um eletrólito indiferente à superfície da bauxita. EmpH 3,48 estimou-se o ponto de carga zero para a bauxita. A análise reológica em termos do parâmetro viscosidade comprovou a influência do $\mathrm{pH}$ na reologia da polpa de bauxita, mostrando que o controle do $\mathrm{pH}$ da polpa em valores distantes ao ponto de carga zero é um fator importante para reduzir a viscosidade e facilitar o transporte por minerodutos. Porém, um afastamento além do desejado poderá promover um desequilíbrio de cargas ao ponto de provocar a sedimentação das partículas, uma vez que uma certa atração entre as cargas deverá ser mantida para assegurar que as partículas permaneçam em suspensão.

\section{AGRADECIMENTOS}

Ao $\mathrm{CNPq}$ pelo apoio à pesquisa e ao desenvolvimento desse trabalho.

\section{REFERÊNCIAS}

[1] L. F. Quaresma, Relatório Técnico 22, Perfil da Mineração de Bauxita, Ministério de Minas e Energia, Brasília, DF (2009) p. 22.

[2] T. L. Valentim, V. P. Lemos, M. H. Pinheiro, K. G. Fernandes, Anais $32^{\mathrm{a}}$ Reunião Anual SBQ, Fortaleza, CE (2009) p. 106.

[3] F. O. Cunha, M. L. Torem, J. C. D’Abreu, Rev. Escola de Minas 60, 3 (2007) 505.

[4] B. V. Van Raij, M. Peech, Soil Sci. Soc. Am. Proc. 36 (1972) 587.

[6] C. A. Coles, R. N. Yong, Appl. Clay Sci. 22 (2002) 39. (Rec. 27/08/2011, Ac. 21/01/2012) 